\title{
Isoflavone supplements stimulated the production of serum equol and decreased the serum dihydrotestosterone levels in healthy male volunteers
}

\author{
M Tanaka ${ }^{1}$, K Fujimoto ${ }^{1}$, Y Chihara ${ }^{1}, \mathrm{~K}_{\text {Torimoto }}{ }^{1}$, T Yoneda $^{1}$, N Tanaka ${ }^{1}$, A Hirayama ${ }^{1}$, N Miyanaga ${ }^{2}$, \\ $\mathrm{H} \mathrm{Akaza}^{2}$ and Y Hirao ${ }^{1}$ \\ ${ }^{1}$ Department of Urology, Nara Medical University, Kashihara, Japan and ${ }^{2}$ Department of Urology, Institute of Clinical Medicine, \\ University of Tsukuba, Tsukuba, Japan
}

\begin{abstract}
The aim of this study was to evaluate the effect of supplementing healthy men with soy isoflavones on the serum levels of sex hormones implicated in prostate cancer development. A total of 28 Japanese healthy volunteers (18 equol producers and 10 equol non-producers) between 30 and 59 years of age were given soy isoflavones $(60 \mathrm{mg}$ daily) supplements for 3 months, and the changes in their sex hormone levels were investigated at the baseline and after administration. The serum and urine concentrations of daidzein, genistein, and the levels of equol in the fasting blood samples and 24-h stored urine samples were also measured. All 28 volunteers completed the 3-month supplementation with isoflavone. No changes in the serum levels of estradiol and total testosterone were detected after 3-month supplementation. The serum levels of sex hormone-binding globulin significantly increased, and the serum levels of free testosterone and dihydrotestosterone (DHT) decreased significantly after 3-month supplementation. Among the 10 equol non-producers, equol became detectable in the serum of two healthy volunteers after 3-month supplementation. This study revealed that short-term administration of soy isoflavones stimulated the production of serum equol and decreased the serum DHT level in Japanese healthy volunteers. These results suggest the possibility of converting equol non-producers to producers by prolonged and consistent soy isoflavones consumption.

Prostate Cancer and Prostatic Diseases (2009) 12, 247-252; doi:10.1038/pcan.2009.10; published online 14 July 2009
\end{abstract}

Keywords: isoflavones; equol; dihydrotestosterone; cancer prevention

\section{Introduction}

Epidemiological studies have shown that the incidences of malignancies, such as prostate cancer, breast cancer and colon cancer, are commonly high in the Western Europe and United States of America, but low in the Asian populations who consume large amounts of soy bean foods. ${ }^{1}$ Soy bean products are rich in isoflavones, such as genistein and daidzein. Isoflavones have been suggested as the principal chemical constituents responsible for the potential preventive effect of soy bean against prostate cancer. ${ }^{2}$ Possible mechanisms have been proposed for the anti-tumor activity of soy isoflavones against prostate cancer, including estrogen-like effects, ${ }^{3}$ prevention of oxidative DNA damage, reduction in cancer cell proliferation ${ }^{5}$ and inhibition of angiogenesis. ${ }^{6}$

Correspondence: Dr M Tanaka, Department of Urology, Nara Medical University, 840 Shijo-cho, Kashihara, Nara 634-8522, Japan.

E-mail: masa-t@naramed-u.ac.jp

Received 28 October 2008; revised 13 March 2009; accepted 13 March 2009; published online 14 July 2009
It has been argued for long whether the lower incidences of prostate cancer among the Asian people are because of the inhibitory effects of isoflavones (contained abundantly in soy beans) and equol (directly metabolized from daidzein by the intestinal bacterial microflora) against prostatic carcinogenesis. Equol has a weak phytoestrogen activity. ${ }^{7}$ Especially, equol and isoflavones have a binding affinity to estrogen receptor $\beta^{8}$ In addition, equol can bind to the sex hormone-binding globulin (SHBG), 9,10 and inhibit the growth of prostate cells in vitro. ${ }^{11,12}$ Therefore, equol can act as an antiandrogen and inhibit the development of sex hormonedependent tumors, such as mammary gland cancer and prostate cancer. ${ }^{12}$ Earlier, we reported that some people can metabolize daidzein into equol, whereas others cannot, and showed that the intake quantity of isoflavones and the proportions of equol producers differed significantly among the races and age stratifications. ${ }^{13}$

In this intervention study, to elucidate the biological impact of isoflavones on equol-producing ability and sex hormonal variation in association with prostate carcinogenesis, we investigated whether the constant daily consumption of isoflavone supplements influenced the 
serum levels of isoflavones, equol and sex hormonal biomarkers in healthy Japanese men.

\section{Participants and methods}

A total of 28 Japanese healthy volunteers (18 equol producers and 10 equol non-producers), between 30 and 59 years of age were given soy isoflavones $(60 \mathrm{mg}$ per day) for 3 months, and the changes in the serum levels of sex hormones, cholesterol and isoflavones were measured at the baseline, and at 1 month and 3 months later. This protocol was designed with reference to earlier studies. ${ }^{14-18}$ This study was conducted to determine the persistence of diet-induced effects on isoflavone metabolism and disposition. Whether a volunteer is an equol producer or non-producer was determined as in our earlier study, in which we conducted a food survey on the daily intake of soybean isoflavone and measured the serum concentrations of isoflavone and equol in all participants. ${ }^{13}$ Five tablets of Isofla A (Fuji Oil Co. Ltd, Osaka, Japan) were administered immediately before breakfast and dinner twice a day to all volunteers. In total, 10 tablets per day contained $60 \mathrm{mg}$ isoflavone, $2.4 \mathrm{~g}$ carbohydrate, $80 \mathrm{mg}$ protein, $70 \mathrm{mg}$ lipid, $100 \mathrm{mg}$ calcium, $60 \mathrm{mg}$ magnesium, $30 \mathrm{IU}$ vitamin D3, and $3 \mathrm{mg}$ vitamin E. Isoflavone $(60 \mathrm{mg})$ consisted of $19.1 \mathrm{mg}$ daidzin, $3.5 \mathrm{mg}$ genistin, $10.4 \mathrm{mg}$ glycitin, $8.1 \mathrm{mg}$ malonyl daidzin, $2.2 \mathrm{mg}$ malonyl genistin, $3.4 \mathrm{mg}$ malonyl glycitin, $7.3 \mathrm{mg}$ acetyl daidzin, $1.9 \mathrm{mg}$ acetyl genistin, $3.6 \mathrm{mg}$ acetyl glycitin, $0.2 \mathrm{mg}$ daidzein, $0.1 \mathrm{mg}$ genistein and $0.3 \mathrm{mg}$ glycitein.

The institutional reviewer board approved this study, and a written informed consent was obtained from all the volunteers. Each volunteer was given packages of Isofla A tablets with a $\log$ at the baseline visit. At 1 month and 3 months later, the residual tablets, used packages and log for counting the residual tablets were collected from all the volunteers to check the intake adherence. The intake of isoflavones from daily foods varied among the volunteers, but they maintained the same life style, including diet, exercise, work and sleep patterns, while being enrolled in this study.

Blood samples at 0800 hours before breakfast (after 10-h fasting) and 24-h urine samples were taken at the baseline, and at 1 month and 3 months after starting isoflavone administration. For all volunteers, blood samples were taken before breakfast, and the separated sera were stored at $-20{ }^{\circ} \mathrm{C}$ or lower. Urine was taken for $24 \mathrm{~h}$ in dark plastic bottles containing $2 \mathrm{~g}$ ascorbic acid, and kept in a cool place during storage. The urine was mixed well and a sample was frozen directly after measuring the volume. These serum and urine samples were subsequently transported on dry ice to the laboratory of SRL Co. Ltd (Tokyo, Japan). The sample size of all volunteers for detecting the serum isoflavone concentration was not calculated, but it was regulated by the feasibility for each investigator.

The concentrations of genistein, daidzein and equol in the serum and urine samples were measured by reversed-phase high-performance liquid chromatography-multiple reaction ion monitoring mass spectrometry. ${ }^{19}$ The serum concentrations of cholesterols (total, high-density lipoproteins and low-density lipoproteins), estradiol, SHBG, total and free testosterone and dihydrotestosterone (DHT) were measured at the same time points at SRL Co. Ltd.

In addition to comparing the serum concentration of isoflavones in the two participant groups, we also compared the participants on the basis of their capability of equol production. The non-producers were defined as having a serum equol concentration below the limit of detection by the present assay system, that is, $0.5 \mathrm{ng} \mathrm{ml}^{-1}$.

Statistical analyses were carried out using non-parametric Wilcoxon's test and $\chi^{2}$-test. A $P$-value of $<0.05$ was considered as representing a statistically significant difference.

\section{Results}

The demographic characteristics of the healthy volunteers are shown in Table 1. Between the equol producers and the non-producers, there was a significant difference in age. All 28 volunteers completed the 3-month isoflavone administration as scheduled. No statistically significant adverse events were reported by the study participants. Diarrhea was the most frequently reported adverse event and occurred in $3(11 \%)$ of the 28 participants. Two participants had diarrhea of grade 1 according to the Common Terminology Criteria for Adverse Events (v3.0) several times during the consecutive 2 days, and one complained of grade 1 diarrhea once only. No participant discontinued the study regimen or withdrew from the study because of these adverse events. The mean adherence rate was more than 99\% during the whole study period. During the 3 months of Isofla A administration, all participants showed no marked change in their life styles.

No significant difference was noticed in the total cholesterol between the mean serum levels at the baseline and the end of study period. Although the mean high-density lipoprotein-cholesterol level at 3 months increased significantly when compared with that of the baseline, the mean low-density lipoproteincholesterol significantly decreased during 3-month isoflavone administration (Table 2). No significant changes in the mean serum levels of estradiol and total testosterone after 3-month administration were noticed when compared with the baseline (Table 2). However, the mean level of SHBG significantly increased after 3 months of isoflavone administration, and the mean serum levels of free testosterone and DHT decreased

Table 1 Demography of healthy male volunteers

\begin{tabular}{lccc}
\hline & $\begin{array}{c}\text { Equol non- } \\
\text { producers } \\
(\mathrm{n}=10)\end{array}$ & $\begin{array}{c}\text { Equol } \\
\text { producers } \\
(\mathrm{n}=18)\end{array}$ & \\
\hline Age (years) & $36.7 \pm 5.2$ & $43.2 \pm 7.8$ & $P<0.05$ \\
Height $(\mathrm{cm})$ & $170.8 \pm 7.3$ & $169.5 \pm 6.9$ & $\mathrm{~ns}$ \\
Weight $(\mathrm{kg})$ & $64.8 \pm 4.1$ & $67.8 \pm 3.9$ & $\mathrm{~ns}$ \\
BMI $\left(\mathrm{kg} \mathrm{m}^{-2}\right)$ & $22.2 \pm 0.6$ & $23.6 \pm 0.7$ & $\mathrm{~ns}$ \\
Former or current smoker & $50.0 \%$ & $55.6 \%$ & $\mathrm{~ns}$ \\
Family history of cancer & $40.0 \%$ & $44.4 \%$ & $\mathrm{~ns}$ \\
Family history of benign & $30.0 \%$ & $31.1 \%$ & $\mathrm{~ns}$ \\
prostatic hyperplasia & & & \\
\hline
\end{tabular}

Abbreviations: BMI, body mass index; ns, non-significant. 
Table 2 Variations of the mean serum levels of cholesterols and sex hormones after isoflavone supplementation

\begin{tabular}{|c|c|c|c|c|}
\hline & Before supplementation & 1 month later & 3 months later & \\
\hline \multicolumn{5}{|l|}{ Serum cholesterol } \\
\hline Total cholesterol (mg per $100 \mathrm{ml}$ ) & $209.0 \pm 35.5$ & $206.7 \pm 30.7$ & $204.5 \pm 31.7$ & ns \\
\hline HDL-cholesterol (mg per $100 \mathrm{ml}$ ) & $55.4 \pm 11.8$ & $57.3 \pm 10.0$ & $59.8 \pm 11.4$ & $P<0.05$ \\
\hline LDL-cholesterol (mg per $100 \mathrm{ml})$ & $132.2 \pm 34.9$ & $127.0 \pm 30.9$ & $118.4 \pm 30.1$ & $P<0.05$ \\
\hline \multicolumn{5}{|l|}{ Serum sex hormones } \\
\hline Estradiol $\left(\mathrm{pg} \mathrm{ml}^{-1}\right)$ & $25.0 \pm 5.6$ & $25.9 \pm 5.6$ & $25.2 \pm 6.5$ & ns \\
\hline Sex hormone-binding globulin $\left(\mathrm{nmoll}^{-1}\right)$ & $52.2 \pm 19.8$ & $47.1 \pm 15.1$ & $61.2 \pm 19.9$ & $P<0.05$ \\
\hline Dihydrotestosterone $\left(\mathrm{ng} \mathrm{ml}^{-1}\right)$ & $0.96 \pm 0.27$ & $0.78 \pm 0.23$ & $0.79 \pm 0.23$ & $P<0.05$ \\
\hline Free testosterone $\left(\mathrm{pg} \mathrm{ml}^{-1}\right)$ & $74.9 \pm 3.5$ & $71.8 \pm 11.9$ & $70.9 \pm 11.2$ & $P<0.05$ \\
\hline Total testosterone $\left(\mathrm{pg} \mathrm{ml}^{-1}\right)$ & $541.0 \pm 125.0$ & $569.0 \pm 108.0$ & $576.0 \pm 135.0$ & ns \\
\hline
\end{tabular}

Abbreviations: HDL, high-density lipoproteins; LDL, low-density lipoproteins; ns, non-significant.

Table 3 Variations of the mean serum and urine levels of genistein, daidzein and equol after isoflavone supplementation

\begin{tabular}{|c|c|c|c|c|}
\hline & Before supplementation & 1 month later & 3 months later & \\
\hline \multicolumn{5}{|l|}{ Serum isoflavone } \\
\hline Genistein $\left(\mathrm{ng} \mathrm{ml}^{-1}\right)$ & $81.7 \pm 80.0$ & $108.0 \pm 106.4$ & $97.6 \pm 97.8$ & $P<0.05$ \\
\hline Daidzein (ng ml ${ }^{-1}$ ) & $40.5 \pm 48.4$ & $132.7 \pm 109.7$ & $133.8 \pm 107.0$ & $P<0.01$ \\
\hline Equol $\left(\mathrm{ng} \mathrm{ml}^{-1}\right)$ & $21.0 \pm 44.8$ & $41.3 \pm 69.7$ & $64.7 \pm 125.9$ & $P<0.01$ \\
\hline \multicolumn{5}{|l|}{ Urine isoflavone } \\
\hline Genistein (nmol per day) & $23.9 \pm 20.5$ & $88.7 \pm 66.7$ & $103.1 \pm 73.7$ & $P<0.01$ \\
\hline Daidzein (nmol per day) & $35.8 \pm 36.2$ & $41.7 \pm 28.7$ & $50.1 \pm 41.6$ & $P<0.05$ \\
\hline Equol (nmol per day) & $12.7 \pm 19.8$ & $36.4 \pm 40.5$ & $37.9 \pm 61.4$ & $P<0.05$ \\
\hline
\end{tabular}

after 3-month administration when compared with the baseline (Table 2).

The mean serum concentration of isoflavones and equol at the baseline, and at 1 month and 3 months after isoflavone administration are shown in Table 3. Genistein increased more significantly in the urine than in the serum. Daidzein and equol showed marked increases in the serum as well as in the urine after 3-month administration. Two equol non-producers became equol producers after 3 months of isoflavone administration. Of these two volunteers, one had serum equol levels of $<0.5 \mathrm{ng} \mathrm{ml}^{-1},<0.5 \mathrm{ng} \mathrm{ml}^{-1}$ and $1.1 \mathrm{ng} \mathrm{ml}^{-1}$, whereas the other had $<0.5 \mathrm{ng} \mathrm{ml}^{-1}, 1.1 \mathrm{ng} \mathrm{ml}^{-1}$ and $24.1 \mathrm{ng} \mathrm{ml}^{-1}$ at the baseline, 1 month, and 3 months after isoflavone administration, respectively.

The mean serum levels of cholesterol, SHBG, estradiol, testosterone and its metabolites were analyzed in the equol producers and non-producers (Table 4). The mean high-density lipoprotein-cholesterol level significantly increased and the mean low-density lipoprotein-cholesterol level showed a significant decrease after 3-month isoflavone administration in the equol producers. Neither the equol producers nor the nonproducers showed any changes in the mean serum level of estradiol during the study period. Equol producers showed a significant increase in the mean SHBG level and a significant decrease in the mean DHT level 3 months later. The free testosterone level showed a significant decrease in the equol producers, but not in the non-producers, whereas the total testosterone level showed no significant increase in both groups.

\section{Discussion}

Prostate cancer has recently become an increasingly important public health issue in Japan. Despite the extensive studies on the pathogenesis and clinical behavior of prostate cancer, the etiological origins or the host-environmental risk factors, which promote its progression, have not yet been well elucidated. ${ }^{20}$ In fact, the African-American men have the highest morbidity rates of prostate cancer in the world, whereas the Asian men natives to their countries, such as the Japanese, Korean and Chinese, have the lowest rates. ${ }^{21}$

However, the incidence of prostate cancer in Japan has recently increased as the diets and life styles became westernized. Although latent or clinically insignificant prostate cancer is detected at a high rate-similar to that in the American men-in autopsy studies on the Asian men, the morbidity rate of clinically significant prostate cancer is 80 -fold higher in USA. ${ }^{22}$ This suggests that the same dietary factors may also promote the progression of latent or microscopic prostate cancer to clinically significant and metastatic prostate cancer. ${ }^{23}$ Some epidemiological studies indicated that the level of dietary soy consumption may be linked to a decreased risk of prostate cancer. ${ }^{24}$ The standard intake of isoflavones by the American men was commonly a couple of milligrams per day. The ninefold decrease in prostate cancer mortality among the Japanese men as compared with that in USA may be attributed, in part, to the high soy protein content in the Japanese diet. ${ }^{25}$

Isofla A tablets are commercially sold in Japan as a supplement, and the most dominant flavonoid was an 
Table 4 Variations of the mean serum levels of cholesterols and sex hormones in equol producers and non-producers after isoflavone supplementation

\begin{tabular}{|c|c|c|c|c|}
\hline & Before supplementation & 1 month later & 3 months later & \\
\hline \multicolumn{5}{|c|}{ Total cholesterol (mg per $100 \mathrm{ml})$} \\
\hline Equol producers & $209.2 \pm 40.1$ & $205.6 \pm 30.2$ & $204.1 \pm 34.3$ & ns \\
\hline Equol non-producers & $208.5 \pm 27.3$ & $208.7 \pm 33.0$ & $205.2 \pm 28.3$ & ns \\
\hline \multicolumn{5}{|c|}{ HDL-cholesterol (mg per $100 \mathrm{ml}$ ) } \\
\hline Equol producers & $53.1 \pm 10.3$ & $56.1 \pm 10.7$ & $57.7 \pm 11.6$ & $P<0.05$ \\
\hline Equol non-producers & $59.5 \pm 13.8$ & $59.5 \pm 8.8$ & $63.5 \pm 10.4$ & ns \\
\hline \multicolumn{5}{|c|}{ LDL-cholesterol (mg per $100 \mathrm{ml}$ ) } \\
\hline Equol producers & $134.9 \pm 38.4$ & $126.3 \pm 31.5$ & $117.1 \pm 30.8$ & $P<0.05$ \\
\hline Equol non-producers & $127.4 \pm 28.9$ & $128.7 \pm 33.0$ & $120.8 \pm 30.3$ & ns \\
\hline \multicolumn{5}{|l|}{ Estradiol $\left(\mathrm{pg} \mathrm{ml}^{-1}\right)$} \\
\hline Equol producers & $24.7 \pm 4.7$ & $25.7 \pm 5.1$ & $24.6 \pm 5.4$ & ns \\
\hline Equol non-producers & $25.5 \pm 7.2$ & $26.3 \pm 6.7$ & $27.0 \pm 7.6$ & ns \\
\hline \multicolumn{5}{|c|}{ Sex hormone-binding globulin $\left(\right.$ nmol $\left.^{-1}\right)$} \\
\hline Equol producers & $50.1 \pm 17.2$ & $45.9 \pm 14.9$ & $60.7 \pm 22.1$ & $P<0.05$ \\
\hline Equol non-producers & $56.1 \pm 24.3$ & $49.3 \pm 15.8$ & $62.0 \pm 16.3$ & ns \\
\hline \multicolumn{5}{|c|}{ Dihydrotestosterone $\left(n g m l^{-1}\right)$} \\
\hline Equol producers & $0.93 \pm 0.25$ & $0.77 \pm 0.24$ & $0.75 \pm 0.18$ & $P<0.05$ \\
\hline Equol non-producers & $1.03 \pm 0.32$ & $0.82 \pm 0.22$ & $0.86 \pm 0.23$ & ns \\
\hline \multicolumn{5}{|l|}{ Free testosterone ( $\left.p g \mathrm{ml}^{-1}\right)$} \\
\hline Equol producers & $74.6 \pm 3.8$ & $74.0 \pm 4.0$ & $70.1 \pm 4.6$ & $P<0.05$ \\
\hline Equol non-producers & $75.4 \pm 3.0$ & $67.8 \pm 19.2$ & $73.6 \pm 2.6$ & ns \\
\hline \multicolumn{5}{|l|}{ Total testosterone $\left(\mathrm{pg} \mathrm{ml}^{-1}\right)$} \\
\hline Equol producers & $529.0 \pm 119.0$ & $564.0 \pm 107.0$ & $541.0 \pm 114.0$ & ns \\
\hline Equol non-producers & $561.0 \pm 140.0$ & $578.0 \pm 114.0$ & $638.0 \pm 153.0$ & ns \\
\hline
\end{tabular}

Abbreviations: HDL, high-density lipoproteins; LDL, low-density lipoproteins; ns, non-significant.

isoflavone glycoside daidzin. The second dominant flavonoid glycitin is an isoflavone glycoside present in foods containing soybean. The metabolite of glycitin synthesized by intestinal microflora is glycitein, which scavenges the intracellular reactive oxygen species. The other ingredients are malonyl or acetyl glycosides and isoflavone aglycones. Diverse bacterial strains of human origin have specific $\beta$-glucosidase and $\beta$-glycuronidase activity in the metabolism of dietary isoflavones from glycosides to aglycones. Aglycone and sulfate of genistein and daidzein have estrogen-like activity and so does equol.

Genistein reportedly inhibits the growth of androgendependent and androgen-independent prostate cancer cell lines ${ }^{26}$ and inhibits the development of prostaterelated cancers in Wistar rats. ${ }^{27}$ The mechanism of action by which genistein exerts this anti-tumor angiogenesis is not well understood. Enough scientific data have accumulated to allow clinical intervention of soy protein in human trials as an adjuvant supplementation for the treatment of prostate cancer, but the optimal and effective doses of soy protein are not yet known. In this study, we also assessed the effects of the daily consumption of isoflavone supplements on the serum highdensity lipoprotein-cholesterol and low-density lipoprotein-cholesterol levels, and measured the isoflavone concentrations in the blood and urine of healthy men. Importantly, our results, as well as those of an earlier study, ${ }^{14}$ supported the hypothesis that the continuous intake of isoflavones is likely to play a promising role in chemoprevention against cardiovascular disease.
In a recent study, it was found that isoflavones could increase the production of SHBG in the liver and bind to biologically active testosterone. Consequently, lowering the free testosterone levels and its bioavailability to the target prostate cells should theoretically halt cancer cell proliferation, inhibit tumor progression and reduce the tumor volume in accordance with the changes in the prostate-specific antigen. ${ }^{16}$ In our study, the SHBG level significantly increased, whereas the free testosterone level and DHT level decreased after 3-month isoflavone administration as compared with the baseline. This result is in consensus with several earlier studies and a recent review on the effects of isoflavone. ${ }^{11,12,28}$

On the other hand, there are some limitations of the product used in our study. The interactions of isoflavones and other nutrients included in Isofla A tablets were not considered. The other ingredients, such as vitamin D or E, may have some effect on SHBG, DHT or testosterone levels, although our earlier study showed that the intake amounts of vitamin D and $\mathrm{E}$ were not risk factors for the development of prostate cancer in Japanese men. ${ }^{29}$ Furthermore, supplementation is usually a high-dose and unbalanced administration unlike the physiological condition, and we donot know whether the supplemental isoflavones behave exactly the same as isoflavones from the actual food, particularly because the intestinal microflora variability or genetic differences in isoflavone metabolism may vary among the individuals or the races. It is still a question how the food substances work in the actual food in comparison with their action in the supplemental form. 
In our earlier case-control study, the ability of producing equol or equol itself closely correlated with the lower incidence of prostate cancer. ${ }^{30}$ At 3 months after soy isoflavone supplementation, serum equol was detected in two healthy volunteers among the equol non-producers group. This suggests the possibility of converting equol non-producers to producers by prolonged and consistent isoflavones consumption. Moreover, prolonged and consistent isoflavones consumption could potentially delay the onset of prostate cancer by interfering with carcinogenesis. A public health initiative now may exist to identify non-toxic therapies for cancer. Several clinical trials evaluated the role of various nutritional supplementations in the treatment of localized prostate cancer. On the basis of updated scientific evidences, numerous nutritional strategies could be used for clinical nutrition interventional trials on the use of individual supplements or dietary modification versus the incorporation of multiple nutritional strategies. As prostate cancer grows relatively slowly in comparison with other malignancies, the potential impact of nutritional intervention may spare patients from undergoing a variety of toxic treatments for prostate cancer, and therefore improve their quality of life. The results of our study warrant further preclinical and clinical trials focusing on the role of isoflavone in chemoprevention against prostate cancer.

\section{Conclusion}

This study revealed that short-term administration of soy isoflavones to Japanese healthy volunteers increased the SHBG level, and decreased the free testosterone and DHT levels. Moreover, equol was detected in the serum of two healthy volunteers among the equol nonproducers group. These results suggest the possibility of converting equol non-producers to producers by prolonged and consistent soy isoflavones consumption, and that a diet based on soy isoflavones will be useful in preventing prostate cancer development.

\section{Conflict of interest}

Isoflavone tablets used in this study were kindly provided by Protein Technologies International (Soybean health Foods Laboratory), Fuji Oil Co. Ltd (Osaka, Japan). This study was supported by a Grant-in-Aid for Scientific Research on Priority Areas, Cancer A-03 and A-04, from the Ministry of Education, Science, Sports and Culture, Japan.

\section{Acknowledgements}

We would like to express our deepest gratitude to the company manager.

\section{References}

1 Adlercreutz $\mathrm{H}$, Honjo $\mathrm{H}$, Higashi A, Fotsis T, Hämäläinen E, Hasegawa $\mathrm{T}$ et al. Urinary excretion of lignans and isoflavonoid phytoestrogens in Japanese men and women consuming a traditional Japanese diet. Am J Clin Nutr 1991; 54: 1093-1100.

2 Zhou JR, Gugger ET, Tanaka T, Guo Y, Blackburn GL, Clinton SK. Soybean phytochemicals inhibit the growth of transplantable human prostate carcinoma and tumor angiogenesis in mice. J Nutr 1999; 129: 1628-1635.

3 Knight DC, Eden JA. A review of the clinical effects of phytoestrogens. Obstet Gynecol 1996; 87: 897-904.

4 Wei H, Cai Q, Rahn RO. Inhibition of UV light-and Fenton reaction -induced oxidative DNA damage by the soybean isoflavone genistein. Carcinogenesis 1996; 17: 73-77.

5 Shao ZM, Alpaugh ML, Fontana JA, Barsky SH. Genistein inhibits proliferation similarly in estrogen receptor-positive and negative human breast carcinoma cell lines characterized by p21WAF1/CIP1 induction, G2/M arrest and apoptosis. J Cell Biochem 1998; 69: 44-54.

6 Fotsis T, Pepper M, Adlercreutz H, Fleischmann G, Hase T, Montesano $\mathrm{R}$ et al. Genistein, a dietary-derived inhibitor of in vitro angiogenesis. Proc Natl Acad Sci USA 1993; 90: 2690-2694.

7 Price KR, Fenwick GR. Naturally occurring oestrogens in foodsa review. Food Addit Contam 1985; 2: 73-106.

8 Petersen DN, Tkalcevic GT, Koza-Taylor PH, Turi TG, Brown TA. Identification of estrogen receptor $\beta 2$, a functional variant of estrogen receptor $\beta$ expressed in normal rat tissues. Endocrinology 1998; 139: 1082-1092.

9 Déchaud H, Ravard C, Claustrat F, de la Perrière AB, Pugeat M. Xenoestrogen interaction with human sex hormone-binding globulin (hSHBG). Steroids 1999; 64: 328-334.

10 Martin ME, Haourigui M, Pelissero C, Benassayag C, Nunez EA. Interactions between phytoestrogens and human sex steroid binding protein. Life Sci 1996; 58: 429-436.

11 Hedlund TE, Johannes WU, Miller GJ. Soy isoflavonoid equol modulates the growth of benign and malignant prostatic epithelial cells in vitro. Prostate 2003; 54: 68-78.

12 Lund TD, Munson DJ, Haldy ME, Setchell KD, Lephart ED, Handa RJ. Equol is a novel anti-androgen that inhibits prostate growth and hormone feedback. Biol Reprod 2004; 70: 1188-1195.

13 Fujimoto K, Tanaka M, Hirao Y, Nagata Y, Mori M, Miyanaga N et al. Age-stratified serum levels of isoflavones and proportion of equol producers in Japanese and Korean healthy men. Prostate Cancer Prostatic Dis 2008; 11: 252-257.

14 Urban D, Irwin W, Kirk M, Markiewicz MA, Myers R, Smith M et al. The effect of isolated soy protein on plasma biomarkers in elderly men with elevated serum prostate specific antigen. J Urol 2001; 165: 294-300.

15 Hussain M, Banerjee M, Sarkar FH, Djuric Z, Pollak MN, Doerge $\mathrm{D}$ et al. Soy isoflavones in the treatment of prostate cancer. Nutr Cancer 2003; 47: 111-117.

16 Kumar NB, Cantor A, Allen K, Riccardi D, Besterman-Dahan K, Seigne J et al. The specific role of isoflavones in reducing prostate cancer risk. Prostate 2004; 59: 141-147.

17 Maskarinec G, Morimoto Y, Hebshi S, Sharma S, Franke AA, Stanczyk FZ. Serum prostate-specific antigen but not testosterone levels decrease in a randomized soy intervention among men. Eur J Clin Nutr 2006; 60: 1423-1429.

18 Kumar NB, Krischer JP, Allen K, Riccardi D, Besterman-Dahan $\mathrm{K}$, Salup $\mathrm{R}$ et al. Safety of purified isoflavones in men with clinically localized prostate cancer. Nutr Cancer 2007; 59: 169-175.

19 Coward L, Kirk M, Albin N. Analysis of plasma isoflavones by reversed-phase HPLC-multiple reaction ion monitoring-mass spectrometry. Clin Chim Acta 1996; 247: 121-142.

20 Carter HB, Coffey DS. The prostate: an increasing medical problem. Prostate 1990; 16: 39-48.

21 Hsing AW, Tsao L, Devesa SS. International trends and patterns of prostate cancer incidence and mortality. Int J Cancer 2000; 85: 60-67.

22 Yatani R, Chigusa I, Akazaki K, Stemmermann GN, Welsh RA, Correa P. Geographic pathology of latent prostatic carcinoma. Int J Cancer 1982; 29: 611-616.

23 Wynder EL, Rose DP, Cohen LA. Nutrition and prostate cancer: a proposal for dietary intervention. Nutr Cancer 1994; 22: 1-10.

24 Oishi K, Okada K, Yoshida O, Yamabe H, Ohno Y, Hayes RB et al. A case-control study of prostatic cancer with reference to dietary habits. Prostate 1988; 12: 179-190.

25 Messina M, Barnes S. The role of soy products in reducing risk of cancer. J Natl Cancer Inst 1991; 83: 541-546. 
26 Peterson G, Barnes S. Genistein and biochanin A inhibit the growth of human prostate cancer cells but not epidermal growth factor receptor tyrosine autophosphorylation. Prostate 1993; 22: 335-345.

27 Pollard M, Wolter W, Sun L. Prevention of induced prostate-related cancer by soy protein isolate/isoflavonesupplemented diet in Lobund-Wistar rats. In Vivo 2000; 14: 389-392.

28 Perabo FG, Von Löw EC, Ellinger J, von Rücker A, Müller SC, Bastian PJ. Soy isoflavone genistein in prevention and treatment of prostate cancer. Prostate Cancer Prostatic Dis 2008; 11: $6-12$.

29 Nagata Y, Sonoda T, Mori M, Miyanaga N, Okumura K, Goto K et al. Dietary isoflavones may protect against prostate cancer in Japanese men. J Nutr 2007; 137: 1974-1979.

30 Akaza H, Miyanaga N, Takashima N, Naito S, Hirao Y, Tsukamoto $\mathrm{T}$ et al. Comparisons of percent equol producers between prostate cancer patients and controls: case-controlled studies of isoflavones in Japanese, Korean and American residents. Jpn J Clin Oncol 2004; 34: 86-89. 